Santa Clara University

Scholar Commons

Psychology

College of Arts \& Sciences

$12-1-2016$

\title{
Principles of incorporating spirituality into professional clinical practice
}

Thomas G. Plante

Santa Clara University, tplante@scu.edu

Follow this and additional works at: http://scholarcommons.scu.edu/psych

Part of the Psychology Commons

\section{Recommended Citation}

Plante, T. G. (2016). Principles of incorporating spirituality into professional clinical practice. Practice Innovations, 1 (4) $276-281$.

Copyright @ 2016 American Psychological Association. http://dx.doi.org/10.1037/pri0000030

This article may not exactly replicate the final version published in the APA journal. It is not the copy of record.

This Article is brought to you for free and open access by the College of Arts \& Sciences at Scholar Commons. It has been accepted for inclusion in

Psychology by an authorized administrator of Scholar Commons. For more information, please contact rscroggin@scu.edu. 
Principles of Incorporating Spirituality into Professional Clinical Practice 


\begin{abstract}
Incorporating spirituality into contemporary professional clinical practice has become more common in recent years most notably with the popular interest of mindfulness meditation, mindfulness based stress reduction, and yoga in particular. However, many other spiritual and religiously based assessment and treatment approaches have also been successfully utilized with a great deal of evidence based research to support their use and effectiveness. The purpose of this brief article is to outline several guiding principles for those professionals interested in integrating spiritual and religious wisdom and approaches into their professional clinical practices in the spirit of diversity and multiculturalism sensitivity and respect. Psychology has a long way to go to overcome biases and prejudice in this area but there are many excellent principles and resources available to help ensure that our clients receive state-of-the-art and effective evidence based professional services that treats them, regardless of their religious and spiritual interests or background, with dignity, respect, and professionalism.
\end{abstract}

Keywords: Spirituality, religion, integrated psychotherapy, clinical practice 
After many decades of neglect and indifference, professional psychology has rediscovered the benefits of spirituality and has become more mindful, respectful, and thoughtful about integrating spirituality into professional clinical practice. Perhaps the best example of this rediscovery of the benefits of spirituality in psychotherapy is the current popular trend of using mindfulness based meditation and stress reduction techniques that has become extremely popular in health care in general and in mental health care in particular. In fact, a recent survey of leaders in the professional psychology field found that mindfulness was the number one trend in all of professional clinical practice (Norcross, Pfund, \& Prochaska, 2013). Mindfulness originated from the Buddhist tradition but has been adapted and secularized so that it is acceptable to a general and diverse audience (e.g., Barker, 2014; Kabat-Zinn, 1990, 1994, 2003; Khoury, Lecomte, Fortin, Masse, Therien, Bouchard, et al., 2013; Langer, 2014). Yet, mindfulness is not alone in being an integrated spiritual practice woven into the fabric of contemporary psychotherapy and professional practice. Yoga, prayer, meditation from other traditions besides mindfulness, mantram training, and so forth have become more commonly integrated into our professional endeavors as well although to a lesser extent than mindfulness (e.g., Bormann, Gifford, Shively, Smith, Redwine, Kelly, et al., 2006; Bormann \& Oman, 2007; Hofmann, 2013; Horovitz \& Elgelid, 2015; Oman, Shapiro, Thoresen, Plante, \& Flinders, 2008; Park, Braun, \& Siegel, 2015; Plante, 2009, 2016; Rajesh, 2015).

While many researchers and practitioners have welcomed these developments, there are many reasons to proceed with a great deal of caution. First, very few past and present graduate and post graduate clinical or counseling students offer any training in integrating spirituality into 
professional clinical services. The vast majority of graduate training programs and clinical internships offer little if any training on this topic. In fact, a recent study found that two-thirds of internship training directors never foresee religion and spirituality incorporated into their professional training programs (Russell \& Yarhouse, 2006). Second, there is little common consensus regarding training in best practices even for those training programs that desire to offer this type of spiritually integrated psychotherapy training opportunities. While there are plenty of quality resources available, little consensus means that training directors, supervisors, and instructors are on their own to determine a curriculum and set of training experiences that they think might be worthwhile and effective (Brawer, Handal, Fabricatore, Roberts, \& WajdaJohnston, 2002). Finally, religion and spirituality can be highly personal and often professionals may be challenged to separate their personal beliefs (or lack of beliefs) and practices from their professional ones. Professional psychology must be evidence based and use well established, scientific, ethical, and best practices interventions that are as free from bias and personal prejudices as humanly possible (American Psychological Association, 2002, 2003).

It is not surprising that professional psychology has been reluctant to integrate spirituality and religious interventions into professional clinical practice. After all, many of the leaders and founding fathers in the field were rather disdainful of religious with Sigmund Freud referring to religion as an “obsessional neurosis (Freud, 1927/1961, p. 43)” while John Watson referred to religion as a "bulwark of medievalism" (Watson, 1924/1983, p. 1). Other leaders such as B. F. Skinner and Albert Ellis were equally negative about religion (e.g., Ellis, 1971). These leaders set the tone for a divide between professional psychology and the religious and spiritual communities and influences that have continued to the present day (Plante, 2009). 
In an effort to provide some guidance for professionals interested in spiritually integrated psychotherapy several key principles are offered in this brief paper. It is important to mention that these principles are not exhaustive by any means but are merely some of the most important strategies and mindset to keep in mind for those interested in spirituality integrated psychotherapy and professional clinical practice. Interested readers can explore these topics in much more detail by reading readily available professional literature in this area (e.g., Pargament, 2007; Pargament, Exline, Jones, Mahoney, \& Shafranske, 2013; Plante, 2009; Sanders, Richards, McBride, Lea, Hardman, \& Barnes, 2015) as well as consult with colleagues and attend professional development continuing education workshops as well.

Before proceeding it is important to define what is meant by spirituality and religion. Spirituality is a broad term encompassing being attentive to what is sacred and connected to a belief, power, or concept greater than oneself as well as highlights a transcendent relationship with what is perceived as being sacred or divine. Religion refers to the organizational and community structures that attempt to provide people with a spiritual environment often highlighting rituals (e.g., liturgy, prayer, fasting), idealized models (e.g., Jesus, Buddha, Mohammad), sacred writings (e.g., the Bible), and particular beliefs and practices (Pargament, 2007; Plante, 2009).

\section{Treat spirituality and religion as a multicultural and diversity issue}

There has been much attention provided toward the critical need and attention to multiculturalism in society in general and within psychology in particular. Quality training in diversity represented by race, ethnicity, gender, gender identity, sexual orientation, and so forth have made great gains in recent years (American Psychological Association, 2003). 
Multiculturalism training is not only expected in graduate and post graduate training but in professional continuing education for license renewal as well. Yet, it is often overlooked that the Code of Ethics from the American Psychological Association mandates respect for and attention to multiculturalism that includes religion and spirituality on par with race, ethnicity, gender, sexual orientation, and so forth (American Psychological Association, 2002). Thus, psychologists have an ethical obligation and duty to learn about and become sensitive to spirituality and religious diversity and risk not fulfilling their obligations under the APA Ethics Code if they fail to do so.

Too often multicultural training, even that of high quality, fails to attend to religious and spiritual diversity focusing their attention much more on ethnicity, race, gender, and sexual orientation instead. It would behoove professional psychology to incorporate spirituality and religious diversity on equal footing with these other types of diversity as demanded in the Code of Ethics. Thus, professionals should consider spirituality and religious diversity in the same manner that they consider, respect, and receive training and consultation about any other forms of diversity. In essence, religious and spiritual diversity should receive equal time as gender, racial, ethnicity, and other forms of diversity and multiculturalism.

\section{Keep biases in check}

Psychology has a long and perhaps sad history of engaging in religious and spiritual discrimination and prejudice. So many leading figures in the field including Sigmund Freud, John Watson, Albert Ellis, B.F. Skinner, among many others have been quoted as being intolerant of religious and spiritual beliefs and practices or at the very least, experiencing them as a sign of psychopathology or ignorance (Ellis, 1971, Freud, 1927/1961, Watson, 1924/1983). 
Research has found that relative to the general population, psychologists tend to be uninterested in and unaffiliated with any religious tradition and typically have few religious beliefs or practices themselves (Delaney, Miller, \& Bisono, 2007; Hage, 2006; Smith \& Orlinsky, 2004).

This history can easily lead to bias, prejudice, and disinterest in the spiritual and religious aspects of their clinical work. While certain particular and often secularized practices such as mindfulness and yoga have received a great deal of acceptance and attention, many other evidence based techniques, perspectives, and practices that are religiously and spiritually informed have not (Plante, 2009, 2016). This includes prayer, religious service attendance, religious community engagement, beliefs in deities, and so forth.

Thus, professional psychologists must always strive to know themselves and be aware of their own biases. This is never easy to accomplish. They must engage in ongoing and thoughtful self-reflection getting consultation as needed to ensure that their biases based on religion and spirituality are always kept in check and not acted upon. Ongoing supervision, regular case consultations with peers, keeping up with the professional literature, attending continuing education workshops and trainings, and being open to corrective feedback and learning new and updates strategies for practice are all important to maintain objective and unbiased approaches to our work. Again, their biases and prejudices based on gender, sexual orientation, race, ethnicity, and so forth need to be considered on par with biases associated with religion and spirituality as well.

\section{Stay within one's area of expertise}

Psychologists and other mental health professionals must always be careful to stay within their areas of expertise and competence. They must ensure that their knowledge and skills remain 
current to be sure that they are always providing their clients with state-of-the-art and evidence based professional service that is current and meets appropriate professional community standards. The Ethics Code makes this clear in section 2.01 regarding Boundaries and Competence and specifically mentioned being mindful of religious diversity stating in section $2.01 \mathrm{~b}$, "Where scientific or professional knowledge in the discipline of psychology establishes that an understanding of factors associated with age, gender, gender identity, race, ethnicity, culture, national origin, religion, sexual orientation, disability, language, or socioeconomic status is essential for effective implementation of their services or research, psychologists have or obtain the training, experience, consultation, or supervision necessary to ensure the competence of their services..." (APA, 2002, Section 2.01b).

This is challenging to do even under the best of circumstances since very little if any training in spirituality and religious diversity is offered in graduate and postgraduate training as well as due to the rapidly changing fields of multiculturalism, diversity, and spirituality integrative psychotherapy. Additionally, well-meaning professionals seeking to integrate spirituality and religion into their professional practices may naively try to do so after very little training or experience. Attending a single continuing education workshop or being a member of a faith tradition doesn't make one an expert to offer these type of professional service. Many people may get swept up in the current trends and fashions (e.g., mindfulness meditation and yoga) and enthusiastically yet naively rush their new found interests and skills into their professional practice activities. Getting quality and ongoing consultation from experts is critical before engaging in spirituality and religiously integrated professional services. 


\section{Refer to experts including clerics}

Most professionals have no trouble referring to or consulting with other professionals in non-psychology fields including medicine, law, education, nursing, and so forth. There is a longstanding history of collegial consultation between psychology and numerous other professionals in health, educational, legal, military, and many other settings.

Yet, curiously, mental health professionals tend not to refer to religious and spiritual experts such as clerics and well as spiritual directors or guides (McMinn, Aikins, \& Lish, 2003; McMinn, Chaddock, Edwards, Lim, \& Campbell, 1998; McMinn, \& Dominquez, 2005). In fact, research suggests that clerical professionals such as pastors, priests, rabbis, imans, and so forth tend to feel dismissed and disrespected by mental health professionals (McMinn et al., 1998).

Thus, it is important for psychologists and all mental health professionals to consider consulting with clerics and other religious and spiritual leaders just as they would with other professionals. Getting to know their local religious community just as they would in getting to know local physicians, teachers, law enforcement, and others depending upon the nature of their clinical practice are important. Attending religious community events and expanding one's list of contacts by networking is helpful as well.

\section{Be aware of best practices and evidence based assessments and interventions}

Fortunately, there is a great deal of quality, evidence based, and published research and best practices when it comes to spiritually and religiously integrated professional practice. Additionally, there are many useful resources including books, videos, workshops, listservs, webinars, and so forth that can help eager and interested professionals improve and enhance their skills. It is critically important for professionals to utilize these available resources and consult 
with experts to be sure that they are aware of and training in these best practices. (Pargament, 2007; Pargament et al., 2013; Plante, 2009; Sanders et al., 2015). Some good examples include Coping with Divorce (Rye \& Pargament, 2003; Rye, Pargament, Pan, Yingling, Shogren, \& Ito, 2005), From Vice to Virtue (Ano, 2005), Recreating Your Life (Cole \& Pargament, 1998), and the Eight Point Program (Easwaran, 1978/1991; Oman et al., 2008).

\section{Use resources where available}

As mentioned, there are numerous resources available for professionals who wish to learn more about integrating spirituality and religion into a multiculturally sensitive and evidence based professional practice. Perhaps a good place to begin is with the APA Division 36 web page and listserv. Division 36 is the Society for the Psychology or Religion and Spirituality and has over 1,000 members. Numerous opportunities are potentially available for advice and collaboration among those who have expertise in this area and are members of this important APA division.

\section{Conclusion}

To provide evidence based and multicultural minded professional clinical practice services it is imperative that professionals consider religion and spirituality in the same way that they might consider other forms of diversity based on gender, race, ethnicity, sexual orientation, and so forth with the APA Ethics Code demanding this attention and respect to religion and spiritual diversity (American Psychological Association, 2002). Yet, too often professionals not only have remarkably little training in religious and spirituality diversity and integrated professional services but are often disinterested in improving their expertise as well. Certainly mindfulness and yoga have been fully embraced by the professional psychological community 
and yet these important and helpful approaches are merely the tip of the iceberg when it comes to evidence based professional services (Plante, 2016). Professionals wishing to serve their clients with high quality and ethical professional services must be aware of and respect spirituality and religion as a multicultural issue, assess their clients' interest and engagement in this important area of human functioning, consult with appropriate colleagues including clerics, and thoughtfully keep whatever biases and prejudices in check. To do otherwise may well be unethical and perhaps risk malpractice. 


\section{References}

American Psychological Association (2002). Ethical principles of psychologists and code of conduct. American Psychologist, 57, 1060-1073.

American Psychological Association (2003). Guidelines on multicultural education, training, research, practice, and organizational change for psychologists. American Psychologist, $58,377-402$.

Ano, G. A. (2005). Spiritual struggles between vice and virtue: A brief psychospiritual intervention. Unpublished doctoral dissertation, Bowling Green State University, Bowling Green, $\mathrm{OH}$.

Barker, K. K. (2014). Mindfulness meditation: Do-it-yourself medicalization of every moment. Social Science \& Medicine, 106, 168-176.

Bormann, J. E., Gifford, A. L., Shively, M., Smith, T. L., Redwine, L., Kelly, A., Becker, S., Gershwin, M., Bone, P., and Belding, W. (2006). Effects of spiritual mantram repetition on HIV outcomes: A randomized controlled trial. Journal of Behavioral Medicine, 29, 359-376.

Bormann, J. E. \& Oman, D. (2007). Mantram or holy name repetition: Health benefits from a portable spiritual practice. In T. G. \& C. E. Thoresen (Eds), Spirit, science and health: How the spiritual mind fuels physical wellness (pp. 94-114). Westport, CT: Praeger/ Greenwood.

Brawer, P.A., Handal, P. J., Fabricatore, A. N., Roberts, R., \& Wajda-Johnston, V. A. (2002). Training and education in religious/spirituality within APA-accredited clinical psychology programs. Professional Psychology: Research and Practice, 33, 203-206. 
Cole, B. S. \& Pargament, K. I. (1998). Re-creating your life: A spiritual/psychotherapeutic intervention for people diagnosed with cancer. Psycho-Oncology, 8, 395-407.

Delaney, H. D., Miller, W. R., \& Bisono, A. M. (2007). Religiosity and spirituality among psychologists: A survey of clinicians members of the American Psychological Association. Professional Psychology: Research and Practice, 38, 538-546.

Easwaran, E. (1991/1978). Meditation: A simple eight-point program for translating spiritual ideals into daily life. Nilgiri Press (full text: http://www.easwaran.org), Tomales, CA. Ellis, A. (1971). The case against religion: A psychotherapist's view. New York: Institute for Rational Living.

Freud, S. (1961). The future of an illusion (J. Strachey, Ed. and Trans.). New York: Norton. (Original work published 1927 by Doubleday).

Hage, S. M. (2006). A closer look at the role of spirituality in psychology training. Professional Psychology: Research and Practice, 37, 303-310.

Hofmann, L. (2013). The impact of Kundalini Yoga on concepts and diagnostic practice in psychology and psychotherapy. In Yoga traveling (pp. 81-106). New York: Springer International Publishing.

Horovitz, E. G., \& Elgelid, S. (Eds.). (2015). Yoga therapy: Theory and practice. New York: Routledge.

Kabat-Zinn, J. (1990). Full catastrophe living. New York: Delacourte Press.

Kabat-Zinn, J. (1994). Wherever you go, there you are. New York, NY: Hyperion.

Kabat-Zinn, J. (2003). Mindfulness-based interventions in context: Past, present, and future. Clinical Psychology: Research and Practice, 10, 144-156. 
Khoury, B., Lecomte, T., Fortin, G., Masse, M., Therien, P., Bouchard, V., ... \& Hofmann, S. G. (2013). Mindfulness-based therapy: A comprehensive meta-analysis. Clinical Psychology Review, 33(6), 763-771.

Langer, E. J. (2014). Mindfulness. Boston: Da Capo Press.

McMinn, M. R., Aikins, D.C., \& Lish, R.A. (2003). Basic and advanced competence in collaborating with clergy: Survey findings and implications. Professional Psychology: Research and Practice, 34, 197-202.

McMinn, M. R., Chaddock, T. P., Edwards, L.C., Lim, R. K. B., \& Campbell, C. D. (1998). Psychologists collaborating with clergy: Survey findings and implications. Professional Psychology: Research and Practice, 29, 564-570.

McMinn, M. R., \& Dominquez, A. W. (2005). Psychology and the church. Hauppauge, NY: Nova Science.

Norcross, J. C., Pfund, R. A., \& Prochaska, J. O. (2013). Psychotherapy in 2022: A Delphi poll on its future. Professional Psychology: Research and Practice, 44(5), 363.

Oman, D., Shapiro, S. L., Thoresen, C. E., Plante, T. G., \& Flinders, T. (2008). Meditation lowers stress and supports forgiveness among college students: A randomized controlled trial. Journal of American College Health, 56, 569-578.

Pargament, K. I. (2007). Spiritually integrated psychotherapy: Understanding and addressing the sacred. New York: Guilford.

Pargament , K., Exline, J., Jones, J., Mahoney, A, \& Shafranske, E. (2013). APA handbooks in psychology: APA handbook of psychology, religion, and spirituality. Washington, DC: American Psychological Association. 
Park, C. L., Braun, T., \& Siegel, T. (2015). Who practices yoga? A systematic review of demographic, health-related, and psychosocial factors associated with yoga practice. Journal of behavioral medicine, 38(3), 460-471.

Plante, T. G. (2009). Spiritual practices in psychotherapy: Thirteen tools for enhancing psychological health. Washington, DC: American Psychological Association

Plante, T. G. (Ed). (2010). Contemplative practices in action: Spirituality, meditation, and health. Santa Barbara, CA: Praeger/ABC-CLIO.

Plante, T. G. (2016). Beyond mindfulness: Expanding integration of spirituality and religion into psychotherapy. Open Theology, 2, 135-144.

Rajesh, S. (2015). Yoga psychology: A handbook of yogic psychotherapy. International Journal of Yoga, 8, 84 .

Russell, S. R., \& Yarhouse, M. A. (2006). Religion/Spirituality within APA-accredited psychology predoctoral internships. Professional Psychology: Research and Practice, 37 (2006): 430-436.

Rye, M. \& Pargament, K. I. (2003). Coping with divorce: A journey toward forgiveness. Unpublished manual, University of Dayton, $\mathrm{OH}$.

Rye, M., Pargament, K. I., Pan, W., Yingling, D. W., Shogren, K. A., \& Ito, M. (2005). Can group interventions facilitate forgiveness of an ex-spouse? A randomized clinical trial. Journal of Consulting and Clinical Psychology, 73, 880-892.

Sanders, P. W., Richards, P. S., McBride, J. A., Lea, T., Hardman, R. K., \& Barnes, D. V. (2015). Processes and outcomes of theistic spiritually oriented psychotherapy: A practicebased evidence investigation. Spirituality in Clinical Practice, 2(3), 180. 
Smith, D. P., \& Orlinsky, D. E. (2004). Religious and spiritual experience among psychotherapists. Psychotherapy, 4, 144-151.

Watson, J. B. (1983). Psychology from the standpoint of a behaviorist. Dover, NH: Frances Pinter (Original work published 1924). 